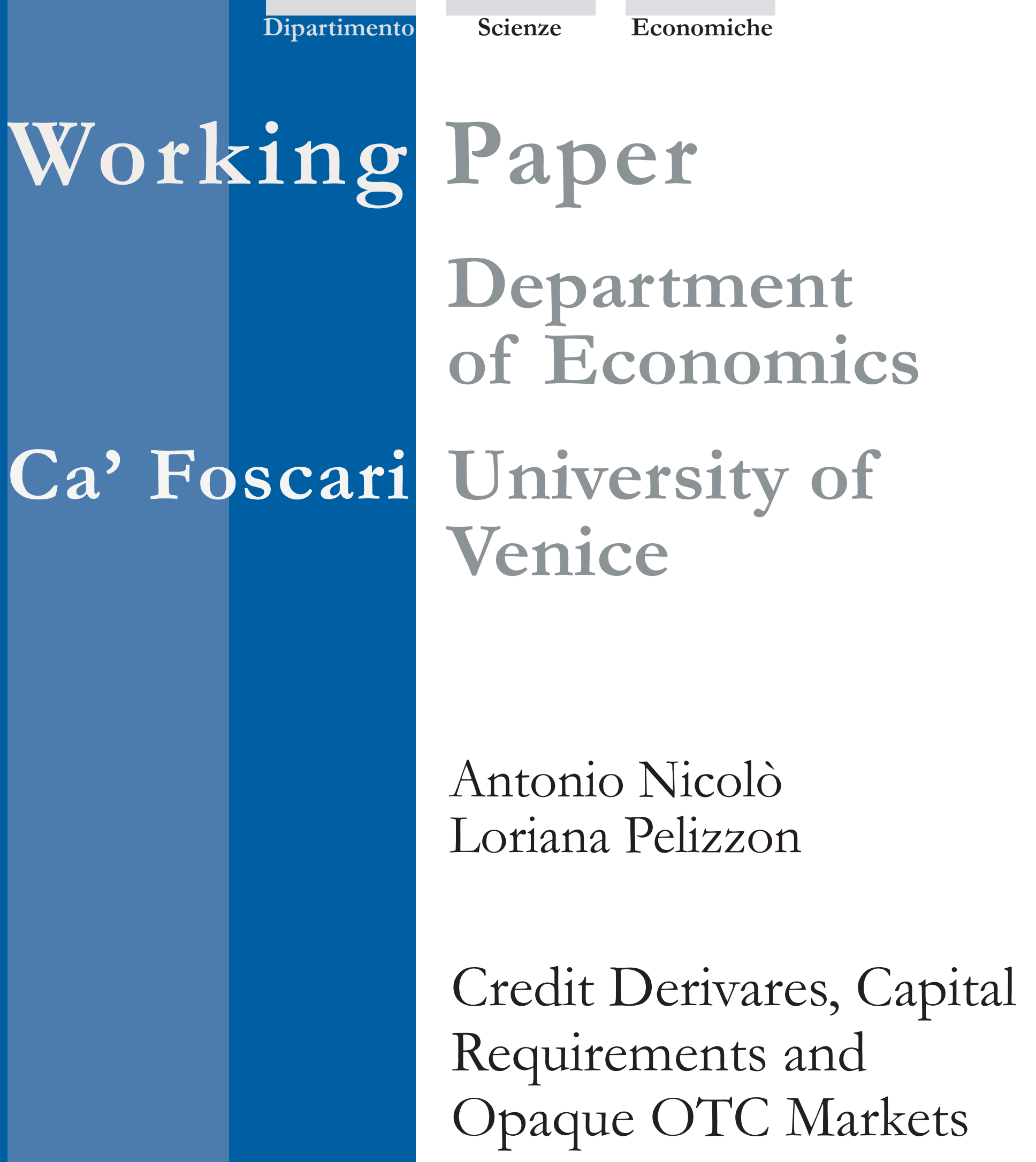




\title{
Credit Derivatives, Capital Requirements and Opaque OTC Markets
}

\author{
Antonio Nicolò \\ University of University of Padua \\ Loriana Pelizzon \\ University of Venice and SSAV
}

First Draft: November 2006

\begin{abstract}
How does bank capital regulation affect the design of credit derivative contracts? How does the opacity of the OTC credit derivative markets affect these contracts? In this paper we address these issues and characterize the optimal security design in several settings. We show that both the level of the banks' cost of capital and the opacity of the credit derivative markets do affect the form of the optimal separating contract and the level of the banks' profits. Moreover, our results suggest that the optimal contracts are largely dependent on bank regulation. More specifically, the introduction of Basel II may prevent the use of the equity tranche in CDO contracts as a signaling device. In addition, the presence of private credit derivative contracts would make the use of signaling contracts able to solve the adverse selection problem quite expensive.
\end{abstract}

\section{Keywords}

Credit derivatives, Signalling contracts, Capital requirements

\section{JEL Codes}

G21, D82

\author{
Address for correspondence: \\ Loriana Pelizzon \\ Department of Economics \\ Ca' Foscari University of Venice \\ Cannaregio 873, Fondamenta S.Giobbe \\ 30121 Venezia - Italy \\ Phone: (++39) 0412349164 \\ Fax: (++39) 0412349176 \\ e-mail: loriana.pelizzon@unive.it
}

This Working Paper is published under the auspices of the Department of Economics of the Ca' Foscari University of Venice. Opinions expressed herein are those of the authors and not those of the Department. The Working Paper series is designed to divulge preliminary or incomplete work, circulated to favour discussion and comments. Citation of this paper should consider its provisional character.

$\begin{aligned} \begin{array}{r}\text { The Working Paper Series } \\ \text { is availble only on line }\end{array} & \begin{array}{l}\text { Department of Economics } \\ \text { Ca' Foscari University of Venice }\end{array} \\ \text { (www.dse.unive.it/pubblicazioni) } & \text { Cannaregio 873, Fondamenta San Giobbe } \\ \text { For editorial correspondence, please contact: } & \text { 30121 Venice Italy } \\ \text { wp.dse@unive.it } & \text { Fax: }++390412349210\end{aligned}$




\section{Introduction}

The recent advent of credit derivatives has provided banks with a whole range of flexible instruments for selling loans and transferring loan risk. For example, pure credit derivatives, such as plain vanilla credit default swaps (CDSs) allow banks to buy protection on a single exposure or on a basket of exposures; portfolio products, such as Collateralized Debt Obligations ${ }^{1}$ (CDOs), enable banks to sell risks from their entire loan portfolio. ${ }^{2}$ One main advantage of these new instruments over traditional forms of credit risk transfer is their flexibility, which helps to mitigate informational problems.

In this paper we investigate the problem faced by banks needing to signal their quality when they use credit risk transfer instruments, a problem that results from the asymmetry of information on their loan portfolios. In line with current market practice, we assume that credit derivative trades are opaque and therefore the banks that need to transfer the credit risk of their loan portfolios (risk-sellers) cannot make a commitment to a specific partial risk holding to signal their quality.

We also assume that banks are subject to minimum regulatory capital requirements and that bank capital is costly. We focus on capital requirements that prevent regulatory arbitrage and help to reduce the probability of bank default. The less-intrusive capital adequacy rule suggested by regulators in pursuit of this objective is that bank capital must cover losses due to loan defaults, with a given probability (see BCBS (2005) commonly known as Basel II, Internal Ratings-Based).

\footnotetext{
${ }^{1} \mathrm{~A}$ CDO is an asset-backed security whose underlying collateral is typically a portfolio of bonds or bank loans. A CDO cash-flow structure allocates interest income and principal repayments from a collateral pool of different debt instruments to a prioritized collection of CDO securities, usually called tranches. A standard prioritization scheme is known as simple subordination: senior CDO tranches are paid before mezzanine and lower-subordinated notes, with any residual cash flow paid to an equity tranche.

${ }^{2}$ Surveys of BBA (2002), BIS (2003, 2005) and Minton, Stulz and Williamson (2005) show that the volume of trade in credit derivatives has known a huge increase in recent years.
} 
These assumptions suggest two research questions that have not yet been considered in the literature to our knowledge. First, how do the different institutional settings (namely, the introduction of new regulatory capital requirements) influence the optimal design of the contracts that risk-sellers may offer to signal their own types? More specifically: is the equity tranche holding, largely used by banks in recent years, an optimal signalling contract under the new Basel II regulatory framework? Second, how does the presence of credit derivatives affect the optimal design when a party cannot credibly commit to retain partial risk holding? Our analysis allows us to answer both questions by determining the optimal security design.

We start by considering the case where the risk-seller can commit to retain some risk. We show that the optimal contract would be similar to selling the loan portfolio and writing a binary credit default basket (Binary CDB), i.e. a credit default basket where the payoff is a fixed dollar amount that could be considered a penalty payment in case defaults are above a certain level. This optimal separating contract leaves the bank with the same level of losses in most of the states of the world in which a default occurs and therefore induces the lowest level of capital requirements for the bank. We show that the fixed dollar amount depends on the cost of capital. In fact, when the cost of capital is increasing, low-type banks have a lower incentive to mimic high-type banks. This implies that the fixed dollar amount that sustains the separating equilibrium is decreasing in the cost of capital. Namely, when the cost of capital goes to infinity the fixed dollar amount that sustains the separating equilibrium is (almost) zero and as also are the capital requirements.

The second setting we consider is when the risk-seller cannot make a credible ex-ante commitment to retain any risk. In this setting, a low-type bank is able to cover the risk of the fixed dollar amount payment (i.e. to hedge the binary credit default basket) 
without allocating bank capital to satisfy capital requirements. Therefore, the cost of capital does not enter into the incentive compatibility constraint of the low-type, and so the fixed dollar amount that sustains the separating equilibrium does not depend on the cost of capital. When the cost of capital is large, high-type banks also prefer hedging the binary credit default basket rather than retaining the risk of such a contract and facing the cost of capital. It follows that in this case the optimal signalling contract is such that there is never a capital loss and therefore the cost of capital is almost zero. This non-negativity constraint reduces the high-type banks' profits in all states of the world, and it may also imply that the pooling equilibrium is preferred by high-type banks.

The above results allow us to investigate the potential implications of different capital adequacy rules on the optimal separating contracts. In fact, we argue that the optimal contracts are largely dependent on bank regulation. The introduction of Basel II may prevent the use of the equity tranche as a signalling device because Basel II will require that all first loss positions be deducted from bank capital and therefore the equity tranche holding would be too costly. Under Basel II, our model suggests that the Binary CDB contract would be optimal. However, as our results show, the opaqueness in the credit derivative market would make the use of this signalling contract quite expensive. In summary, the introduction of Basel II may change the optimal signalling contract characteristics and the opacity of the credit derivative OTC markets will increase the cost of the signalling contract.

Note that later on we do not distinguish between opaqueness in trading (more related to CDS markets) and problems in pre-commitment to retaining risk (more related to CDO markets). Since the effects in terms of contract design are the same we refer to them without distinctions. 
The paper is organized as follows. The next section describes the related literature. In Section 3 we present the basic model and we analyze the benchmark case with symmetric information. In Section 4 we consider the asymmetric information case and we present our results. In Section 5 we present some regulatory implications. Section 6 concludes.

\section{Related literature}

The tremendous development in credit derivative markets has received the attention of both regulators and policy makers. Most international and national supervisors have published reports on the topic (e.g. IMF (2002), BIS (2003, 2005)). However, the majority of the concerns are on a purely informal basis, which is due to the lack of theoretical work on these issues. Exceptions are Duffee and Zhou (2001), Morrison (2005), and Parlour and Plantin (2005).

Duffee and Zhou (2001) demonstrate that the problem of adverse selection may be overcome by drawing up credit derivatives with a smaller maturity than that of the underlying asset. ${ }^{3}$ The key assumption in their model is the hypothesis that the bank's information advantage changes over time and, in particular, is greater when it is close to the maturity date of the loan. Our approach is different, because we assume neither that the bank's information advantage decreases over time, nor that there is perfect observability of credit derivative contracts.

Morrison (2005) shows that if credit derivative trades are opaque, so that the protection buyer cannot make an ex-ante commitment to a specific protection level, banks have a moral hazard incentive to hedge their exposure fully and therefore cease to monitor. This behavior has the negative effect of causing disintermediation and thus reducing

\footnotetext{
${ }^{3}$ Moreover, Duffee and Zhou (2001) show that the mechanism, proposed by Gorton and Pennacchi (1995) to reduce the moral hazard problem associated with the loan sales, is broadly applicable to any mechanism that transfers loan risk outside of the bank, including credit derivatives.
} 
welfare. In our paper we take a different approach than Morrison (2005) because we investigate the adverse selection problem and show how the opacity in the credit derivative markets matters in the optimal credit derivatives design. ${ }^{4}$

Parlour and Plantin (2005) consider the effect of credit risk transfer on relationship banking. They concentrate on the optimal mix of equity, bonds, and loans, and show that liquidity effects can arise endogenously in credit derivative markets when banks are net protection buyers. As for Duffie and Zou (2001) and Morrison (2005), Parlour and Plantin (2005) concentrate on the CDS market and in contrast to our paper, they do not address the security design issue.

Even ignoring the capital requirement issue and the contract observability problem, the theoretical literature on credit derivatives and the problem of asymmetries of information is limited. DeMarzo and Duffie (1999) and DeMarzo (2005) focus on liquidity problems with asymmetric information. More precisely, they have shown that, in line with Leland and Pyle (1977), pooling and sharing may be optimal when the protection buyer has superior information. They argue that the sharing process allows the protection buyer to concentrate the "lemon's premium" on the small first-loss or equity tranche and create a relatively large, low-risk senior tranche. Also, the risk-seller's retention of the subordinate tranche reduces the total lemon's premium by creating an incentive for the risk-seller to align its interests with those of the risk-buyers. The main difference with our work is that we rule out the possibility of using the quantity of the security sold on the market as a signalling device, due to the opacity of the credit derivative market. Security issuers may only signal their own type by offering different contracts, but they cannot credibly commit to retain a portion of the security. In DeMarzo and

\footnotetext{
${ }^{4}$ Chiesa (2005) shows that Morrison's (2005) problem could be solved using an optimal credit risk transfer instrument, i.e. transferring exogenous risk. In this way the bank lowers the amount of capital that it must put at stake for finding an incentive-compatible mechanism to monitor/screen the loans it originates.
} 
Duffie (1999), pre-design information does not affect results, roughly speaking, because the quantity is "the best signal" the issuer can use to signal its own type. In our setting, in which we rule out the possibility of using the quantity sold as a signal of the issuer's type, the assumption of pre-design asymmetric information turns out to be fundamental. Moreover, in our model we focus on costs induced by capital requirements based on maximum losses due to loan default and not on frictions generated by expected liquidity costs. Finally, as a minor difference between the two models, we allow the (re)payment due to the buyer of the security to be larger than the cash-flow of the asset. Thus, we allow for contracts that are not feasible in a setting (like that of DeMarzo and Duffie (1999)) in which the signalling contracts' cash flows are restricted so as to be lower than those of the underlying portfolio in all states. ${ }^{5}$ Because of these three main differences, the optimal signaling contract we find is quite different than the one of DeMarzo and Duffie (1999).

\section{The model}

\subsection{Assumptions}

Let us consider a market where there is a bank (risk-seller) operating in the local loan market, which may hedge its exposures in the credit derivative market by selling credit risk to other financial institutions (risk-buyers).

Risk-sellers and risk-buyers are both risk neutral and, for simplicity, the riskless interest rate is zero. The risk-seller belongs to one of two different bank types: high-

\footnotetext{
${ }^{5}$ For a more complete overview of the issues that arise with various instruments for credit risk transfer see Kiff, Michaud and Mitchell (2003). For studies that assume symmetric information and investigate risk-sharing effects see Allen and Carletti (2006). Empirical evidence on asymmetries of information and insider trading in the CDS markets and on why banks use credit derivatives are provided respectively by Acharya and Johnson (2005) and Minton et al. (2005).
} 
type (denoted by $h$ ) and low-type (denoted by $l$ ). Both types vary only with respect to the quality of their loan pools for the credit risk on which the bank seeks protection. The quality of the pools is assumed to depend on borrowers' ability to repay loans and therefore the risk-seller's quality can be represented by the probability that its borrowers repay loans. This probability is greater for a high-type risk-buyer than for a low-type. Let $p_{i}$ for $i=\{h, l\}$ be the probability of success for loan repayment, then $0 \leq p_{l}<p_{h} \leq 1$, where $p_{l}$ and $p_{h}$ are the probability of loan success held by a low-type and a high-type risk-seller, respectively.

The model incorporates two dates: 0 and 1 . On date 0 , the risk-seller holds a portfolio of two commercial loans with fixed size: $I_{1}$ and $I_{2}$, which mature on date 1 . Both credit lines can default only at the maturity date and are uncorrelated. ${ }^{6}$ For simplicity, we assume here that the recovery value is equal to zero. Moreover, all the cash flows occur at the maturity of the contracts.

Making a loan of amount $I$, a risk-seller $i=\{h, l\}$ obtains an expected profit $E \pi_{i}=$ $p_{i}(1+\mu) I-I$, where $\mu$ is the interest rate, which is the same for both types. Hence, risk-buyers cannot infer risk-sellers' types from the interest rate. ${ }^{7}$ Moreover, we assume that $\mu \leq 1$; this assumption allows us to simplify our analysis and is sufficiently mild not to undermine the generality of our results. We assume that $E \pi_{h}>E \pi_{l} \geq 0$, that is both types of loans have non-negative net present value (NPV)). The loan portfolio cash flows $S$ are characterized by 4 states; State 1: no default $\left(S_{1}=\left(I_{1}+I_{2}\right)(1+\mu)\right)$, and the three default states, State 2: default of only loan $1\left(S_{2}=I_{2}(1+\mu)\right)$, State 3 : default of only loan $2\left(S_{3}=I_{1}(1+\mu)\right)$, State 4 : default on both loans $\left(S_{4}=0\right)$.

\footnotetext{
${ }^{6}$ The key aspects of the paper are not based on diversification opportunities; the assumption that there are no other assets in the bank's portfolio allows us to present our results in a very simple framework focussing on the use of credit derivatives to cover exposures.

${ }^{7}$ This assumption is in line with the statement of Duffee and Zhou (2001), according to which there is no one-to-one relation between the interest rate charged by a bank and the quality of borrowers. We can assume that the interest rate were determined at some stage earlier than date 0 of the model and now loans may have changed in quality.
} 
Banks finance the portfolio of loans with deposits. Therefore, losses will push the bank toward insolvency if it has insufficient capital to cover them. Because of either deadweight costs generated by insolvency or capital requirements, the bank, even if risk neutral, cares about risk and holds capital as a buffer to cover losses or to satisfy capital requirements. We assume that bank capital is invested in a short term asset and is not used to finance the portfolio of loans. Moreover, although bank shareholders are risk neutral, the cost of capital, denoted by $\rho$, is assumed to be greater ${ }^{8}$ than the cost of deposits, which is normalized to zero. ${ }^{9}$

These assumptions simplify the model considerably because we do not need to model explicitly the bank's capital structure nor its capital adequacy rules in detail but we refer more generally to the bank capital needed to prevent default, with a given probability $\alpha$. We assume ${ }^{10}$ that $\alpha>p_{h}$ and this implies that the bank capital has to cover all losses.

Here we focus on the case in which banks use credit derivatives in order to reduce capital requirements and therefore the cost of capital. The credit derivative market we consider is characterized by the presence of different types of contracts. At time 0 , the risk-seller simultaneously offers credit derivative contracts to the risk-buyers. ${ }^{11}$ Since there are many risk-buyers, we assume that the risk-seller faces a competitive market. At the time of the proposal, the risk-seller's type is private information. Hence, we assume that the risk-seller has full bargaining power and makes a take-it or leave-it offer to a risk-buyer. Finally, let $0<q<100 \%$ be the percentage of high-quality banks among the risk-sellers.

\footnotetext{
${ }^{8}$ See Dewatripont and Tirole (1993), Froot and Stein (1998) and Gorton and Winton (1998) for explicit models of why $\rho$ might be positive.

${ }^{9}$ Introducing a positive flat deposit insurance premium would reduce the spread by the cost of capital but this extra cost will be reflected in the cost of loans without altering our results.

${ }^{10}$ Under Basel II, $\alpha$ is set at $99.9 \%$.

${ }^{11} \mathrm{We}$ assume that protection sellers are not subject to capital requirements because, in line with empirical evidence, they are largely insurance companies or hedge funds (see BIS (2005)).
} 


\subsection{The benchmark case: symmetric information}

If a bank is issuing a portfolio of loans $\left(I_{1}, I_{2}\right)$, its maximum loss, with a confidence level $\alpha$, is $I_{1}+I_{2}$ that we observe in State 4 given our assumption that the recovery rate is zero (i.e. capital requirements are $I_{1}+I_{2}$ ). Under this framework, in order to prevent default (or satisfy capital requirements) the bank has to guarantee loan losses with bank capital equal to $I_{1}+I_{2}$. Let $E \pi_{i}$ denote the expected profits of a bank of quality $i=\{h, l\}$ when it does not transfer its risk. We have:

$$
E \pi_{i}=p_{i}\left(I_{1}+I_{2}\right)(1+\mu)-\left(I_{1}+I_{2}\right)-\rho\left(I_{1}+I_{2}\right) \text { with } i=h, l,
$$

where $\rho\left(I_{1}+I_{2}\right)$ is the required remuneration for the bank capital buffer that guarantees loan losses. In order to reduce loan losses and therefore the capital buffer, the bank can sign credit derivatives. In our model, the credit event is identified with a failure to pay at the maturity date. The credit event payment is defined as the difference between the nominal value plus the accrued interest and the recovery value of the defaulted loan that is equal to zero in our framework. Moreover, we assume that all the cash flows (including payment of the premiums) occur at the maturity of the contracts.

When the risk-seller's type is common knowledge, then the lowest premium that a risk neutral risk-buyer is willing to accept is the fair premium. Hence, the lowest premium that will fully insure a bank of type $i$ with loan $I_{j}$ by means of a plain vanilla CDS contract is:

$$
\Phi_{i}\left(I_{j}\right)=\left(1-p_{i}\right) I_{j}(1+\mu) \text { with } i=h, l \text { and } j=1,2 \text {. }
$$


Signing a CDS basket contract on the bank's loan portfolio, the expected profits of a risk-seller of type $i$, denoted $E \pi_{i}(C D S)$, are:

$$
E \pi_{i}(C D S)=\mu\left(I_{1}+I_{2}\right)-\Phi_{i}\left(I_{1}\right)-\Phi_{i}\left(I_{2}\right) \text { with } i=h, l .
$$

Observe that loan losses are completely covered by the CDS basket and therefore there are no capital requirements and no costs of capital. Since by assumption the NPV of the loans is positive for both types $i=h, l$, it follows that expected profits are positive.

It is straightforward to note that, with complete information, the full coverage CDS basket is a first-best contract.

\section{Asymmetric information}

\subsection{Pooling equilibria}

In any pooling equilibrium the minimal premium that a risk-buyer is willing to accept in order to sign a plain vanilla contract that fully hedges the counterpart against the credit risk of the loan $I_{j}$ is:

$$
\Omega\left(I_{j}\right)=q\left(1-p_{h}\right) I_{j}(1+\mu)+(1-q)\left(1-p_{l}\right) I_{j}(1+\mu) \text { with } j=1,2 .
$$

Signing a full coverage CDS basket, a risk-seller of type $i$ obtains the following expected profit:

$$
E \pi_{i}(F C P L)=\mu I_{j}-\Omega\left(I_{j}\right) \text { with } i=h, l \text { and } j=1,2 \text {. }
$$

As usual, it is easy to find the pooling equilibrium where both types of risk-sellers sign the same contract. In particular, it is straightforward to check that there exists a pooling 
equilibrium such that risk-sellers of both types sign the CDS basket. The risk-buyer's beliefs are such that, if a full coverage CDS basket is offered, the risk-seller is a high-type with probability $q$; if any contract different than a full coverage CDS basket is offered, then the risk-seller is a low-type with probability 1. It is clear that high-type banks' profits are lower than their profits in a game with complete information and the lower the number of high-type banks in the market, the stronger is the incentive to signal their own type. We devote the next section to analyzing separating equilibria.

\subsection{Separating equilibria}

In this section we prove the existence of separating equilibria and we show how the optimal separating contract varies according to the presence of capital requirements and the ability of the banks to commit to retaining some risk that high-type banks use to signal their own types. We restrict our attention to contracts according to which a bank, in order to satisfy capital requirements, sells its loans by creating a security. The payoff of the security, $F$, is made contingent on the outcome of the unique verifiable signal, the cash flows of the loans, i.e. $F(S)$. The design of the security may vary and we define the optimal security as that which maximizes the security issuer's profits. Let $P$ be the price of the security.

\subsubsection{The benchmark case: optimal separating contract with no cost of capital}

In our framework, when capital is costless a bank has no incentive to create a security. However, the case of costless capital is a useful benchmark for analyzing how the presence of capital constraints and the opacity of the credit derivative market affect the optimal design of the security. Since both the risk-sellers and the risk-buyers are risk neutral 
there exist different forms for transferring the risk, which are equivalent in term of welfare, all of them providing the first-best level of profits $\left(p_{h}(1+\mu)-1\right)\left(I_{1}+I_{2}\right)$ to the high-type bank. One optimal credit derivative is the trivial contract such that the bank sells its loans at price $P^{P S}=\left(I_{1}+I_{2}\right)(1+\mu)$, and it commits to insuring the risk-buyer fully (that is, to repay $I(1+\mu)$ in case of default of loan $I$ ). More formally, the bank sells its loan portfolio and writes a Put with strike price $K=\left(I_{1}+I_{2}\right)(1+\mu)$, i.e. $F(S)=\max (K-S, 0)$ and the contract is $\left[P^{P S}, \max (K-S, 0)\right]$.

Another credit derivative contract, which is useful to highlight in order to compare it with the optimal separating contracts when the capital is costly, is the binary credit default basket contract (Binary CDB). According to this security, the issuer commits to pay a fixed dollar amount $L$ to the risk-buyer in case of default of any loan, where the amount $L$ is fixed and independent with respect to the loss suffered by the risk-buyer, i.e. $F(S)=\left(L \mid S<\left(I_{1}+I_{2}\right)(1+\mu)\right)$. The optimal credit derivative contract $\left[P^{N C}, L^{N C}\right]$ is such that:

$$
P^{N C}=\left(I_{1}+I_{2}\right)(1+\mu)\left(\frac{1+p_{h} p_{l}}{p_{h}+p_{l}}\right)
$$

and:

$$
L^{N C}=\frac{\left(I_{1}+I_{2}\right)(1+\mu)}{\left(p_{h}+p_{l}\right)} .
$$

The following proposition summarizes the above discussion:

Proposition 1 When bank capital is costless, there exists a separating equilibrium where high-type banks issue a credit derivative that guarantees to them the first-best level of profits; low-type banks offer a plain vanilla contract.

Proof. See the appendix. 
Remark 1 This separating equilibrium is the unique perfect Bayesian equilibrium satisfying the Cho-Kreps intuitive criterion.

In order to overcome the multiplicity of perfect Bayesian equilibria, we only consider separating equilibria that satisfy the intuitive criterion proposed by Cho and Kreps (1987) for a signalling game (denoted "CK-criterion"). Given that we employ this refinement concept several times, it is worth giving an informal intuition of how it works. Consider that a risk-seller makes an out-of-equilibrium proposal and consider any conjecture that it has about how the risk-buyer reacts. If it happens that, given the risk-buyer's most optimistic conjecture (the risk-buyer believes that the proposer is a high-type bank, with probability one), a high-type bank finds it optimal to deviate while the low-type does not, then the intuitive criterion assigns probability 1 that the proposer of such a contract is a high-type bank.

\subsubsection{The optimal separating contract with costly capital}

When bank capital is costly the trivial contract $\left[P^{P S}, \max (K-S, 0)\right]$ is clearly no more an optimal separating contract. In fact, it induces a maximum capital loss equal to $\left(I_{1}+I_{2}\right)$ for the issuer of the security. The contract $\left[P^{N C}, L^{N C}\right]$ performs better since the induced maximum capital loss is equal to:

$$
R^{N C}=\left(L^{N C}+\left(I_{1}+I_{2}\right)-P^{N C}\right)=\left(I_{1}+I_{2}\right)\left(\frac{\left(p_{h}+p_{l}\right)-(1+\mu) p_{h} p_{l}}{p_{h}+p_{l}}\right)
$$

which is positive but lower than $\left(I_{1}+I_{2}\right)$. However, this is not the optimal contract since the amount of capital loss that a high-type bank needs to signal its own type should optimally depend upon the cost of capital $\rho$. In fact, the larger the cost of capital, the larger also is the cost for the low-type bank in mimicking the high-type. To find the 
optimal security, recall that both risk-buyers and risk-sellers are risk-neutral. Therefore the issuer optimally splits up an equal repayment in all states of the world in which at least one default occurs, in order to minimize the total loss. It is worth noting that the default of one loan occurs with probability $2 p_{i}\left(1-p_{i}\right)$ for a bank of type $i$. It follows from our assumption that, conditioned on the event "only one default" occurred, the probability that the bank is low-type is larger than the probability that the issuer is a high-type. ${ }^{12}$

Therefore, the optimal contract will be the separating contract that leaves the hightype bank the same, lowest, payoff in the three default states as shown in the following proposition:

Proposition 2 When bank capital is costly, the optimal separating contract for hightype banks is the binary credit default basket contract $\left[P^{C}, L^{C}\right]$ such that:

$$
L^{C}=\frac{\left(I_{1}+I_{2}\right)(1+\mu)\left(p_{h}(1+\rho)-p_{l}\right)-\rho\left(I_{1}+I_{2}\right)}{p_{h}^{2}(1+\rho)-p_{l}^{2}}
$$

and:

$$
P^{C}=\left(1-p_{h}^{2}\right) \frac{\left(I_{1}+I_{2}\right)(1+\mu)\left(p_{h}(1+\rho)-p_{l}\right)-\rho\left(I_{1}+I_{2}\right)}{p_{h}^{2}(1+\rho)-p_{l}^{2}}+p_{h}\left(I_{1}+I_{2}\right)(1+\mu)
$$

where $P^{C}$ is the price paid by the risk-buyer for buying the bank portfolio and $L^{C}$ is the amount that the risk-seller has to pay in case of default of any loan.

Proof. See the appendix.

\footnotetext{
${ }^{12}$ The event "one default" occurs with higher probability for a low-type bank than a high-type if the following holds: $p_{h}+p_{l}>1$, which follows by our assumptions that the low-type NPV is positive and $\mu<1$.
} 
Remark 2 The unique separating equilibrium that satisfies the CK-criterion is such that high-type banks offer the contract $\left[P^{C}, L^{C}\right]$ and low-type banks offer the plain vanilla contract. Risk-buyers' beliefs are such that a risk-seller is high-type if it offers the optimal separating contract $\left[P^{C}, L^{C}\right]$, it is a low-type otherwise.

In this case the high-type banks face a maximum capital loss equal to:

$$
\left(\frac{\left(p_{h}-p_{l}\right)\left(\left(p_{h}+p_{l}\right)\left(I_{1}+I_{2}\right)-p_{h} p_{l}\left(I_{1}+I_{2}\right)(1+\mu)\right)}{\left(p_{h}^{2}(1+\rho)-p_{l}^{2}\right)}\right)=R^{C}
$$

where we denote by $R^{C}$ the maximum capital loss induced by the contract $\left[P^{C}, L^{C}\right]$ that is lower than $R^{N C}$.

Let $E \pi_{h}\left(P^{C}, L^{C}\right)$ denote the high-type bank's expected profit in signing the contract $\left[P^{C}, L^{C}\right]$; we have that:

$$
E \pi_{h}\left(P^{C}, L^{C}\right)=\left(I_{1}+I_{2}\right)\left(p_{h}(1+\mu)-1\right)-\rho R^{C}
$$

i.e. the expected level of profits is equal to the first-best level, less the cost of capital.

A high-type bank signals its type by committing to pay a fixed penalty in case of default of one loan. This signal turns out to be costly when bank capital itself is costly, but the cost for the high-type bank is lower than it faces with the contract $\left[P^{N C}, L^{N C}\right]$. Not surprisingly, we have that $L^{C}=L^{N C}$ if $\rho=0$, while it is worth noticing that $\frac{\partial R^{C}}{\partial \rho}<0$, that is, the maximum capital loss is decreasing in the cost of capital $\rho$ since it enters into the low-type bank's self-selection constraint and therefore it reduces the incentive for the low-type bank to sign this type of contract. In particular, $R^{C}$ tends to zero when the cost of capital tends to infinity. The optimal separating contract when capital is costly is no longer a first-best contract due to the presence of the capital 
requirements. This affects the level of high-type bank profits and the set of optimal contracts shrinks to only those with a fixed dollar amount repayment.

\subsubsection{The optimal separating contract when capital is costly and the credit derivative market is opaque}

As we showed above, the optimal separating contract $\left[P^{C}, L^{C}\right]$ depends on the cost of capital $\rho$. Unfortunately this occurs only if the risk-seller is able to commit itself to sustain this cost of capital in the future. From now on, we assume that a bank cannot commit to retain such a cost. A contract in which a bank commits to retain this cost is not verifiable in front of a court, even if it may be observed by those who bought fractions of this security. It follows that the cost of capital $\rho$ cannot appear in the self-selection constraint for the low-type bank. In fact a low-type bank, after having sold the Binary CDB can buy a hedging contract at price $\left(1-p_{l}^{2}\right)$ per unit of fixed dollar amount in case of default and avoid the cost of capital $\rho R^{C}$. The combination of the credit derivative contract $\left[P^{C}, L^{C}\right]$ and a contract hedging $L^{C}$ provides larger expected profits to the lowtype bank than hedging the loan portfolio with the CDS basket, and therefore provides an incentive to mimic the high-type bank. All the more so, the same reasoning holds when credit derivative contracts are private, and therefore the party who buys a portion of the security cannot even observe if the seller of the security secretly hedges $L^{C}$ with some other risk-buyers. Since trading in the Binary CDB market is relatively opaque, it appears that observability is the main relevant issue we are considering here, and for this reason we stress this aspect.

Lemma 1 If the credit derivative market is opaque then the contract $\left[P^{C}, L^{C}\right]$ does not sustain a separating equilibrium.

Proof. See the appendix. 
The opacity of the credit derivative market makes more costly for high-type banks to signal their own type. In fact, the cost of capital enters no more into the self-selection constraint of a low-type bank since it can always hedge its exposures. Therefore the lack of commitment has an impact on both the optimal separating contract and the level of profits of the high-quality banks.

Proposition 3 When bank capital is costly and the credit derivative market is opaque, if $\rho \leq \frac{\left(p_{h}^{2}-p_{l}^{2}\right)}{p_{l}^{2}}$, the optimal separating contract for high-type banks is the contract $\left[P^{N C}, L^{N C}\right]$, which is the optimal separating contract with fixed payment when capital is costless. If $\rho>\frac{\left(p_{h}^{2}-p_{l}^{2}\right)}{p_{l}^{2}}$, then the optimal separating contract is:

$$
P^{O}=\frac{\left(I_{1}+I_{2}\right)\left(p_{l}(1+\mu)-1+p_{l}^{2}\right)}{p_{l}^{2}},
$$

and:

$$
L^{O}=\frac{\left(I_{1}+I_{2}\right)\left(p_{l}(1+\mu)-1\right)}{p_{l}^{2}} .
$$

Proof. See the appendix.

It is easy to provide an intuition for this result. The cost of capital does not enter into the self-selection constraint. Low-type agents can in fact hedge the Binary CDB. Therefore, there are only two types of credit derivative contracts that can credibly sustain a separating contract. The first type is the contract $\left[P^{N C}, L^{N C}\right]$, which is the credit derivative contract that sustains the separating equilibrium when capital is costless. Nevertheless, now the high-type banks face a positive cost of capital equal to $\rho R^{N C}>0$, as we argued above. The second type of contract is the contract $\left[P^{O}, L^{O}\right]$, which is a separating contract where high-type banks also face no capital cost since, as can be 
easily checked, $R^{O}=L^{O}+\left(I_{1}+I_{2}\right)-P^{O}=0$. The high-type banks' expected profits when they sign the contract $\left[P^{O}, L^{O}\right]$ are:

$$
E \pi_{h}\left(P^{O}, L^{O}\right)=p_{h}^{2} \frac{\left(I_{1}+I_{2}\right)\left(p_{l}(1+\mu)-1\right)}{p_{l}^{2}}
$$

The contract $\left[P^{O}, L^{O}\right]$ provides less profit than the contracts $\left[P^{C}, L^{C}\right]$ and $\left[P^{N C}, L^{N C}\right]$ to the high-type banks, indeed $E \pi_{h}\left(P^{C}, L^{C}\right)>E \pi_{h}\left(P^{N C}, L^{N C}\right)>E \pi_{h}\left(P^{O}, L^{O}\right)$. In fact, the contract $\left[P^{O}, L^{O}\right]$ is constrained by the non-negativity of the bank profits in all the states (and especially in the worst state of the world) and therefore capital requirements are equal to zero. A high-type bank cannot use the signalling content implicit in the retention of some costly risk, i.e. a risk that generates a positive cost of capital. Since the signal is less powerful, separation can only be obtained by reducing the price $P$ at which the loans are sold, thereby reducing the incentive of the low-type bank in buying this type of contract. The contract $\left[P^{N C}, L^{N C}\right]$ can sustain a separating equilibrium only if high-type banks prefer to face the cost of capital, rather than hedging their capital loss as would a low-type bank.

Let $X$ denote the amount of coverage in case of default gained by a bank that buys a hedging contract at price $\left(1-p_{l}^{2}\right) X$ to avoid the cost of capital. We have that $X$ satisfies the following equation:

$$
X-\left(1-p_{l}^{2}\right) X-R^{N C}=0,
$$

that is,

$$
X=\frac{R^{N C}}{p_{l}^{2}} .
$$


The additional expected cost for a high-type bank, which buys a hedging contract of amount $X$ as a low-type bank is given by:

$$
X\left(1-p_{h}^{2}\right)-X\left(1-p_{l}^{2}\right)=-X\left(p_{h}^{2}-p_{l}^{2}\right)
$$

and therefore the contract $\left[P^{N C}, L^{N C}\right]$ is a separating contract only if the expected cost of hedging the loss as a low-type bank is lower than or equal to the expected cost of the capital loss, that is:

$$
X\left(p_{h}^{2}-p_{l}^{2}\right) \leq \rho R^{N C}
$$

Substituting (17) in (19) and dividing by the maximum capital loss $R^{N C}$ we have:

$$
\rho \geq \frac{\left(p_{h}^{2}-p_{l}^{2}\right)}{p_{l}^{2}}
$$

When the bank capital is costly and the credit derivative market is opaque we have two cases. If $\rho \leq \frac{\left(p_{h}^{2}-p_{l}^{2}\right)}{p_{l}^{2}}$ then the unique CK-separating equilibrium is such that high-type banks offer the contract $\left[P^{N C}, L^{N C}\right]$, and low-type banks offer a plain vanilla contract at their fair price. Risk-buyers' beliefs are such that a risk-seller is high-type if it offers the contract $\left[P^{N C}, L^{N C}\right]$, it is a low-type otherwise. If $\rho>\frac{\left(p_{h}^{2}-p_{l}^{2}\right)}{p_{l}^{2}}$, then the unique CK-separating equilibrium is such that high-type banks offer the contract $\left[P^{O}, L^{O}\right]$ and low-type banks offer a plain vanilla contract at their fair price. Risk-buyers' beliefs are such that a risk-seller is high-type if it offers the contract $\left[P^{O}, L^{O}\right]$, it is a low-type otherwise.

The level of profits that a high-type bank can obtain by signing the $\left[P^{O}, L^{O}\right]$ contract is not only lower than the first best level of profits, but it can be even lower than the level of profits the high-type obtains in the pooling equilibrium. 
Lemma 2 If $\rho>\frac{\left(p_{h}^{2}-p_{l}^{2}\right)}{p_{l}^{2}}, q>\frac{p_{h}^{2}\left(\frac{(1+\mu)}{p_{l}}-p_{l}^{2}\right)-\mu-\left(1-p_{l}\right)(1+\mu)}{\left(p_{h}-p_{l}\right)(1+\mu)}$ and the credit derivative market is opaque, then the high-type banks' profits are larger in the pooling equilibrium than in the optimal separating equilibrium.

Proof. See the appendix.

\subsection{A simple extension to the continuous case}

Up to now, we considered a simple discrete case where the only publicly observable signal is the default of the loans in the portfolio. We consider in this section a slightly more general model where the initial investment of the bank on the loan portfolio is $I$ and the public observable signal is the realized cash flows of the loan portfolio, which is assumed to be a continuous random variable $s \in[0, M]$, where $M$ is the maximum cash flow generated when all loans are repaid. Hence, we model the security as a continuous and differentiable function $g(s):[0, M] \rightarrow \mathbb{R}_{+}$which specifies the non-negative amount that the risk-seller pays to the risk-buyer for any realization of the cash flow $s$ of the loan portfolio. Let $\bar{s} \in \arg \max g(s)$, that is $g(\bar{s})$ is the maximum amount that the riskseller agrees to pay to the risk-buyer ${ }^{13}$, which is relevant to the determination of capital requirements. Let $\rho$ indicate, as usual, the cost of capital due to the presence of capital requirements and $F_{i}(s)\left(f_{i}(s)\right)$ denote the conditional distribution (density) function of $s$ given type $i=h, l$. Let $E_{i}(s)$ be the expected cash-flow of the loan portfolio if the issuer is of type $i$. A contract is a pair $[P, g(s)]$, where $P$ is the price paid to the issuer of the security. Consider directly the case where the credit derivative market is opaque. A high-type bank that wants to offer a separating contract has to solve the following problem:

\footnotetext{
${ }^{13}$ For the sake of simplicity we extend the confidence level of capital requirements to $100 \%$ rather than $99.9 \%$.
} 


$$
\max _{\{g(s), P\}} P-I-\int_{0}^{M} g(s) f_{h}(s) d s+\rho(\min \{0, P-I-g(\bar{s})\})
$$

s.t.

$$
\begin{gathered}
\int_{0}^{M} g(s) f_{h}(s) d s+\int_{0}^{M} s f_{h}(s) d s-P \geq 0 \\
P-\int_{0}^{M} g(s) f_{l}(s) d s \leq \int_{0}^{M} s f_{l}(s) d s
\end{gathered}
$$

$$
\bar{s} \in \arg \max g(s)
$$

Note that the cost of capital does not enter into the incentive compatibility constraint, since the low-type bank can secretly hedge any portion of the security. The solution to the problem depends upon the specification of the conditional density functions $f_{i}(s)$ for $i=h, l$. We provide here a sufficient condition that allows a similar result to the discrete case to be obtained. Namely, we assume that there exists $s_{0} \in[0, M]$ such that $0<f_{h}(s) \leq f_{l}(s)$ for all $s \leq s_{0}$ and $f_{h}(s)>f_{l}(s)>0$ for all $s>s_{0}$.

Proposition 4 If there exists a separating equilibrium, then the optimal separating contract for the high-type banks is a pair $(P, g(s))$ where (i) $g(s)=\frac{E_{h}(s)-E_{l}(s)}{F_{l}\left(s_{0}\right)-F_{h}\left(s_{0}\right)}=k$ for all $s \leq s_{0}$ and $g(s)=0$ for all $s>s_{0} ;$ (ii) $P=\frac{E_{h}(s) F_{l}\left(s_{0}\right)-E_{l}(s) F_{h}\left(s_{0}\right)}{F_{l}\left(s_{0}\right)-F_{h}\left(s_{0}\right)}$.

Proof. See the appendix.

Proposition (4) states that the optimal contract under the continuous distribution of loan payoffs is still a Binary CDB where, if realization of loan repayments is below $s_{0}$, the issuer has to pay a fixed amount $k$. This is in line with the optimal contract in the discrete payoff case. 


\section{Regulatory implications}

The optimal contracts we have described above fit well with many of the contracts we observe in the market. The contract $\left[P^{P S}, \max (K-S, 0)\right]$ is similar to a CDO where the risk-seller retains the equity tranche in order to signal its type. The $[P, L]$ is similar to a contract where the bank sells the loan portfolio and commits to pay a fixed dollar amount if losses are above a certain level, i.e. it writes a Binary CDB.

In this section we investigate whether the different institutional settings may influence the structure of optimal signalling contracts and therefore the demand of different credit derivatives for capital requirements reduction. ${ }^{14}$

In the last two decades we have observed an attempt to change bank capital regulation. In the early 1980s, as concerns for the financial health of international banks mounted and complaints of unfair competition increased, the Basel Committee on Banking Supervision initiated a discussion on the revision of capital standards. An agreement was reached in July 1988. The 1988 Basel Accord (Basel I, BCBS (1998)) explicitly considered only credit risk and imposed an $8 \%$ capital requirement on risk-adjusted assets. ${ }^{15}$ The guidelines do not recognize credit derivatives explicitly. However, the emergence of credit derivative markets has been treated with cautious support by regulators and, to date, in order to cover this gap in the regulation, there have been a number of official pronouncements on the regulation of credit derivatives. ${ }^{16}$

The basic approach taken by regulators is to draw analogies with more conventional instruments for which a well developed regulatory framework already exists.

\footnotetext{
${ }^{14}$ Note that credit derivatives' demand is related not only to capital requirements but also to liquidity problems. For an overview and an empirical analysis of why banks use credit derivatives see Minton et al. (2005).

${ }^{15}$ Risk-adjusted assets are defined as a weighted sum of bank assets whose weights depend on asset risk buckets. See Cooke (1990) for the debate that leads to the Accord, BCBS (2005) for the Accord and its amendments, and Pelizzon and Schaefer (2005) for a detailed description of the main advantages and drawbacks of the new Accord.

${ }^{16}$ For an overview of regulatory announcements, see Staehle and Cumming (1999).
} 
One aspect that needs to be considered is that under Basel I, in most jurisdictions, CDOs are considered as a portfolio of loan sales and banks face almost no capital requirements for holding the equity tranche.

This setting is similar to the case where the required capital for holding the equity tranche has a cost equal to zero. Indeed, in this case, holding the equity tranche is a first-best contract. This implies that under Basel I, high-quality banks can optimally use the equity tranche holding to signal their own type.

However, following its introduction, the Accord has been fine-tuned to accommodate financial innovation and to reflect some risks not initially considered. In particular, (see BCBS (2005)) a new approach, Basel II, has recently been proposed to take into account some of the limitations of the earlier framework.

More specifically, the introduction of Basel II capital adequacy rules requires for CDOs that all first-loss positions must be deducted from bank capital. ${ }^{17}$ This requirement is similar to our framework with costly capital. Our results indicate that the introduction of such a capital requirement may prevent the use of the equity tranche holding and other contracts characterized by loss smoothing will be optimal signalling device. An example of such contracts would be the Binary CDB where the fixed dollar amount paid is largely dependent on the cost of capital. However, the optimality of such a contract under Basel II capital adequacy rules could be compromised by the opacity in the OTC credit derivative markets that may prevent the use of credit derivatives as a signalling device if the cost of capital is large. In fact, the presence of opacity implies that it is easier for low-type banks to mimic high-type ones. Therefore the separating contract would still be a Binary CDB but it will be more costly for the high-type banks.

\footnotetext{
${ }^{17}$ See BCBS (2005), page 48.
} 
Hence, when the cost of capital is sufficiently large, high-type banks may prefer not to signal their type.

\section{Concluding remarks}

In this paper we investigate how the implementation of different capital requirement settings affects the design of the contracts that risk-sellers may offer to signal their own type.

Using a simple model we show that the existence of a credit derivative market together with capital requirements for credit risk induces an adverse selection problem because low-type banks may cover their exposure with credit derivatives. Hence, the introduction of a credit derivative market does not necessarily always benefit the economy. We determine the optimal separating contract and show that such a contract is different according to whether the bank capital is costless, or is costly and whether the credit derivative market is opaque. In particular, we show that when bank capital is costly, and capital requirements are based on maximum losses given a certain confidence level, the optimal contract would be similar to selling the loan portfolio and writing a binary credit default basket, i.e. a credit default basket where the payoff is a fixed dollar amount that could be considered a penalty payment in case defaults are beyond some level.

However, this result holds only if the risk-seller can commit to retaining some risk. When the cost of capital is large and the credit derivative market is opaque, the use of signalling contracts could be quite costly. In fact, banks cannot, credibly commit to retain any risk to signal their own type, and therefore the induced cost of capital has no signalling content. Therefore, high-type banks may face a cost of capital in writing 
a Binary CDB large enough to destroy the incentive for high-type banks to signal their own type, since they have larger profits in the pooling equilibrium, than in the separating one.

To our knowledge this is the first paper in the academic literature that considers rigorously the implications for the design of credit derivatives contracts of two characteristics: capital requirements and opacity of the credit derivative markets.

Our model has a number of implications for regulators. Under Basel I, high-quality banks can issue CDO contracts and hold the equity tranches to signal their own type. This is because there is almost no capital requirements for holding the equity tranche. However, the introduction of Basel II may prevent the use of the equity tranche holding as signalling device. The optimal separating contract in this case would be a binary credit default basket. Moreover, the presence of private credit derivative contracts would make the use of signalling contracts able to solve the adverse selection problem quite expensive.

We believe that these results are relevant since they show that theoretical predictions may change depending whether credit derivative market is opaque or not. Since the assumption that credit derivative markets are opaque seems much more plausible, our results suggest that the analysis of this market may deserve further investigation.

\section{References}

[1] Acharya V. and T. Johnson (2005), Insider Trading in Credit Derivatives, forthcoming, Journal of Financial Economics.

[2] Allen F. and E. Carletti (2006), Credit Risk Transfer and Contagion, Journal of Monetary Economics, 53, 89-111.

[3] BBA (2002), British Bankers Association, Credit Derivatives Report.

[4] BCBS (1988), Basel Committee on Banking Supervision, International Convergence of Capital Measurements and Capital Standards, Basel.

[5] BCBS (2005), Basel Committee on Banking Supervision International Convergence of Capital Measurements and Capital Standards: A revised framework, Basel. 
[6] BIS (2003), Bank for International Settlement, Credit Risk Transfer: Committee on the Global Financial System, Working Paper, January.

[7] BIS (2005), Bank for International Settlement, Credit Risk Transfer: Committee on the Global Financial System, Working Paper, March.

[8] Chiesa G. (2005), Risk Transfer, Lending Capacity and Real Investment Activity, Working paper, Department of Economics, University of Bologna.

[9] Cho, I.K. and D.M. Kreps (1987), Signaling Games and Stable Equilibria, Quarterly Journal of Economics, 102, 179-221.

[10] Cooke P. (1990), International Convergence of Capital Adequacy Measurement and Standards. in The Future of Financial Systems and Services: Essays in Honor of Jack Revel, eds. E. P. M. Garden, New York: St Martin's Press, 310-335.

[11] DeMarzo P. (2005), The Pooling and Tranching of Securities: A Model of Informed Intermediation, Review of Financial Studies, 18, 1-35.

[12] DeMarzo P. and D. Duffie (1999), A Liquidity-based Model of Security Design, Econometrica, 67, 65-99.

[13] Dewatripont M. and J. Tirole (1993), The Prudential Regulation of Banks, MIT Press.

[14] Duffee, G. R. and C. Zhou (2001), Credit Derivatives in Banking: Useful Tools for Managing Risk?, Journal of Monetary Economics 48(1), 25-54.

[15] Froot K. and J. Stein (1998), Risk Management, Capital Budgeting and Capital Structure Policy for Financial Institutions: an Integrated Approach, Journal of Financial Economics, 47, 55-82.

[16] Gorton, G. B. and G. Pennacchi (1995), Banks and loan sales: Marketing nonmarketable assets, Journal of Monetary Economics, 35, 389-411.

[17] Gorton G. and A. Winton (1998), Liquidity Provision, The Cost of Bank Capital and the Macroeconomic, NBER Working Paper.

[18] IMF (2002), International Monetary Funds: Global Financial Stability Report. A Quarterly Report on Market Developments and Issues.

[19] Jaffee, D. and T. Russel (1976), Imperfect Information, Uncertainty, and Credit Rationing, Quarterly Journal of Economics, 90, 651-666.

[20] Kiff, J, F. L. Michaud and J. Mitchell (2003), Instruments of credit risk transfer: effects on financial contracting and financial stability, NBB Working Paper.

[21] Leland, H. E. and D. H. Pyle (1977), "Informational Asymmetries, financial structure and financial intermediation" Journal Finance, 32, 371-387.

[22] Minton B., R. Stulz and R. Williamson (2005), How much do banks use credit derivatives to reduce risk? NBER Working paper 11579.

[23] Morrison A. (2005), Credit Derivatives, Disintermediation and Investment Decisions, Journal of Business, 78, 2, 621-647. 
[24] Parlour, C. and G. Plantin (2005), "Credit Risk Transfer," Working paper, Tepper School of Business, Carnegie Mellon University.

[25] Pelizzon L. and S. Schaefer (2005), Pillar 1 vs Pillar 2 under risk management. In: M. Carey and R. Stulz (Eds) Risks of Financial Institutions and of the Financial Sector, Oxford Press.

[26] Staehle D. and C. Cumming (1999), The supervision of credit derivative activities of banking organizations. In: J.C. Francis, J.A. Frost, J.G. Whittaker (Eds) Handbook of Credit Derivatives, McGraw-Hill, New York, 293-326.

[27] Stiglitz, J. E. and A. Weiss (1981), Credit Rationing in Markets with Imperfect Information, American Economic Review, 71, 393-410.

\section{Appendix}

Proof of Proposition 1: We show that there exists a separating contract $[P, F(S)]$ that provides first-best level of profits to high-type banks. We consider first the case where $F(S)=\eta(\max (K-S, 0))$. In such a contract a bank sells its loans $I_{1}$ and $I_{2}$ to the risk buyer at price $P$, and it commits to cover a fraction $\eta$ of the risk-buyer's losses in case of default of any loan. A separating equilibrium has to satisfy both the participation constraint for the risk-buyer, such that its expected profits are non negative, and the self-selection constraint for the low-type, such that its expected profits are not larger when it offers the $[P, \eta(\max (K-S, 0))]$ contract than when it offers a CDS basket at its fair price.

Namely, the optimal separating contract $\left[P^{P S}, \eta(\max (K-S, 0))\right]$ satisfies the following problem:

$$
\max _{\{P, \eta\}} P-\left(1-p_{h}\right) p_{h} \eta\left(I_{1}+I_{2}\right)(1+\mu)-\left(1-p_{h}\right)^{2} \eta\left(I_{1}+I_{2}\right)(1+\mu)
$$

s.t.

$$
\begin{gathered}
P-\eta\left(I_{1}+I_{2}\right)(1+\mu)\left(\left(1-p_{l}\right) p_{l}+\left(1-p_{l}\right)^{2}\right) \leq p_{l}\left(I_{1}+I_{2}\right)(1+\mu) \\
\eta\left(I_{1}+I_{2}\right)(1+\mu)\left(1-p_{h}\right)+p_{h}\left(I_{1}+I_{2}\right)(1+\mu)-P \geq 0
\end{gathered}
$$

Given the linearity of the problem, the solution can be easily obtained by solving the two constraints as equality and we obtain $\eta=1$ and $P^{P S}=\left(I_{1}+I_{2}\right)(\mu+1)$ and the 
high-type bank's expected profits are equal to $E \pi_{h}=p_{h}\left(I_{1}+I_{2}\right)(\mu+1)$, which are, of course, the first-best level of profits for high-type banks. The separating equilibrium that satisfies the CK-criterion is the strategy profile in which high-type banks offer the above described $\left[P^{P S}, \max (K-S, 0)\right]$ contract and low-type banks offer full-coverage plain vanilla contracts at the fair price $\left(1-p_{l}\right)\left(I_{1}+I_{2}\right)$. Risk-buyer beliefs are such that a bank is high-type with probability 1 if it offers the $\left[\left(I_{1}+I_{2}\right)(1+\mu), \max (K-S, 0)\right]$ contract; it is a low-type with probability one otherwise. It is easy to check that these beliefs satisfy the intuitive criterion. To check uniqueness (in welfare terms), note that in any separating equilibrium where the price offered is $P^{\prime}<P^{P S}$, there exists $P^{\prime} \leq P^{\prime \prime}<\bar{P}$ such that if a high-type bank deviates by offering a contract $\left[P^{\prime \prime}, \max (K-S, 0)\right]$, then by the intuitive criterion a risk-buyer should assign probability one that the proposer is a high-type bank, since this contract provides positive profits only to high-type banks. The same argument holds for any separating $[P, \eta(\max (K-S, 0)]$ contract with different $\eta$

Nevertheless, note that there are other contracts that are separating and present the same expected profits for the high-type bank. For example the contract $[P, L]$ where $L$ is a flat refund payment in case of any default (i.e. $F(S)=L \mid S<\left(I_{1}+I_{2}\right)(1+\mu)$ ) and $P$ is the price offered for the two loans (a Binary CDB contract).

The maximum price that the counterpart agrees to pay is equal to the expected profits of the loans minus the expected payment it receives in case of default of any of the underlying assets. The optimal separating contract $\left[P^{N C}, L^{N C}\right]$ satisfies the following problem:

$$
\max _{\{P, L\}} P-\left(1-p_{h}^{2}\right) L
$$

s.t.

$$
\begin{gathered}
P-\left(1-p_{l}^{2}\right) L \leq p_{l}\left(I_{1}+I_{2}\right)(1+\mu) \\
p_{h}\left(I_{1}+I_{2}\right)(1+\mu)+\left(1-p_{h}^{2}\right) L-P \geq 0
\end{gathered}
$$


The solution of the problem is straightforward since it satisfies the above constraints as equality:

$$
\begin{gathered}
L^{N C}=\frac{\left(I_{1}+I_{2}\right)(1+\mu)}{\left(p_{h}+p_{l}\right)} \\
P^{N C}=\left(I_{1}+I_{2}\right)(1+\mu)\left(\frac{1+p_{h} p_{l}}{p_{h}+p_{l}}\right) .
\end{gathered}
$$

and it provides the same expected payoff to the high-type bank as the contract $\left[P^{P S}\right.$, $\max (K-S, 0)]$ i.e. $E \pi_{h}=p_{h}\left(I_{1}+I_{2}\right)(\mu+1)$. Therefore, it is an optimal separating contract.

More specifically, it follows that there exists a separating $\left[P^{N C}, L^{N C}\right]$ contract such that high-type banks sell loans $I_{1}$ and $I_{2}$ in exchange for an amount of money equal to $P^{N C}$ and commit to pay $L^{N C}$ in case of the default of any loan. Low-type banks sign full coverage plain vanilla contracts paying the fair premium $\left(1-p_{l}\right)\left(I_{1}+I_{2}\right)(1+\mu)$. The equilibrium beliefs are such that the risk buyer believes that the bank is high-type if and only if it offers to sign a $\left[P^{N C}, L^{N C}\right]$ contract. It is easy to check that these beliefs satisfy the intuitive criterion.

Proof of Proposition 2: We first prove that the optimal separating contract provides for a flat repayment in case any default occurs. We denote by $L_{1}$ the amount of repayment in case only one default occurs and by $L_{2}$ the amount of the repayment in case both assets default. The optimal separating contract $\left[P, L_{1}, L_{2}\right]$ solves the following problem:

$$
\max _{\left\{P, L_{1}, L_{2}\right\}} P-\left(1-p_{h}\right)^{2} L_{2}-2 p_{h}\left(1-p_{h}\right) L_{1}-\rho\left(\max 0, L_{2}+\left(I_{1}+I_{2}\right)-P\right)-\left(I_{1}+I_{2}\right)
$$

s.t.

$$
\begin{gathered}
P-\left(1-p_{l}\right)^{2} L_{2}-2 p_{l}\left(1-p_{l}\right) L_{1}-\rho\left(\max 0, L_{2}+\left(I_{1}+I_{2}\right)-P\right) \\
\leq p_{l}\left(I_{1}+I_{2}\right)(1+\mu)
\end{gathered}
$$




$$
\begin{gathered}
\left(1-p_{h}\right)^{2} L_{2}+2 p_{h}\left(1-p_{h}\right) L_{1}-P+p_{h}\left(I_{1}+I_{2}\right)(1+\mu) \geq 0 \\
L_{2}-L_{1} \geq 0 \\
L_{1} \geq 0 .
\end{gathered}
$$

First order conditions are:

$$
\begin{gathered}
1+\rho-\lambda(1+\rho)-\mu=0 \\
\delta-\left(1-p_{h}\right)^{2}-\rho+\lambda\left(1-p_{l}^{2}\right)+\lambda \rho+\mu\left(1-p_{h}\right)^{2}=0 \\
\gamma-2 p_{h}\left(1-p_{h}\right)+\lambda 2 p_{l}\left(1-p_{l}\right)+\mu 2 p_{h}\left(1-p_{h}\right)-\delta=0 .
\end{gathered}
$$

Suppose first that $\delta=0$ (and therefore $L_{2}>L_{1}$ ). From (38):

$$
\mu=(1+\rho)(1-\lambda)
$$

and therefore it must be that $\lambda<1$. Substituting in (39) we obtain:

$$
\lambda=\frac{1}{(1+\rho)\left(1-\left(1-p_{h}\right)^{2}\right)-p_{l}^{2}} \rho\left(1-\left(1-p_{h}\right)^{2}\right)
$$

and substituting in (41) we can easily check that $\lambda<1$. Substituting (42) and (41) in (40) we have that:

$$
\gamma=2 \rho p_{h}\left(1-p_{h}\right)(\lambda-1)-2 \lambda\left(p_{h}-p_{l}\right)\left(p_{h}+p_{l}-1\right)
$$

Since we proved that $\lambda<1$, the first term is negative. If $p_{h}+p_{l}>1$ the second term is also negative, reaching the desired contradiction. We assumed that the NPV is positive for both types $\left(p_{l}>\frac{1}{1+\mu}\right)$, that $\mu<1$ and therefore these are sufficient conditions for $p_{h}+p_{l}>1$. In the same way we reach a contradiction when $L_{1}>L_{2}$ is assumed. Hence, to find the optimal separating contract we simply solve the following system of equations:

$$
\begin{gathered}
P-\left(1-p_{l}^{2}\right) L-\rho\left(\max 0, L+\left(I_{1}+I_{2}\right)-P\right)-p_{l}\left(I_{1}+I_{2}\right)(1+\mu)=0 \\
\left(1-p_{h}^{2}\right) L-P+p_{h}\left(I_{1}+I_{2}\right)(1+\mu)=0 .
\end{gathered}
$$


It follows that the optimal separating contract $\left[P^{C}, L^{C}\right]$ is such that:

$$
L^{C}=\frac{\left(I_{1}+I_{2}\right)(1+\mu)\left(p_{h}(1+\rho)-p_{l}\right)-\rho\left(I_{1}+I_{2}\right)}{\left(p_{h}^{2}(1+\rho)-p_{l}^{2}\right)}
$$

and:

$$
P^{C}=\left(1-p_{h}^{2}\right) \frac{\left(I_{1}+I_{2}\right)(1+\mu)\left(\left(p_{h}(1+\rho)-p_{l}\right)-\rho\left(I_{1}+I_{2}\right)\right.}{\left(p_{h}^{2}(1+\rho)-p_{l}^{2}\right)}+p_{h}\left(I_{1}+I_{2}\right)(1+\mu) .
$$

Note that the optimal separating contract $\left[P^{C}, L^{C}\right]$ implies that the risk-seller has negative payoff in the worst state of the world (that is when both loans default), in fact:

$$
P^{C}-L^{C}-\left(I_{1}+I_{2}\right)=\left(I_{1}+I_{2}\right)\left((1+\mu) p_{h} p_{l}-\left(p_{h}+p_{l}\right)\right)<0
$$

if and only if $\mu<\frac{p_{h}+p_{l}-p_{h} p_{l}}{p_{h} p_{l}}$, which holds by the assumption that $\mu<1$. Therefore there is no contract which satisfies the above constraint as equality such that there is no cost of capital.

It is easy to check that indeed the high-type bank has a capital requirement different than zero since $P^{C}-L^{C}-\left(I_{1}+I_{2}\right)<0$. Moreover $L^{C}=L$ if $\rho=0$ and $\frac{\partial L^{C}}{\partial \rho}<0$. Let $R^{C} \equiv L^{C}+\left(I_{1}+I_{2}\right)-P^{C}$ denote the capital requirement. We have that:

$$
R^{C}=\frac{\left(p_{h}-p_{l}\right)\left(\left(p_{h}+p_{l}\right)\left(I_{1}+I_{2}\right)-p_{h} p_{l}\left(I_{1}+I_{2}\right)(1+\mu)\right)}{\left(p_{h}^{2}(1+\rho)-p_{l}^{2}\right)}
$$

and therefore $\underset{\lim \rho \rightarrow \infty}{R}=0$ and $\lim _{\rho \rightarrow \infty} R^{C}=\frac{\left(I_{1}+I_{2}\right)\left(p_{h}(1+\mu)-1\right)}{p_{h}^{2}}$.

Let $E \pi_{h}\left(P^{C}, L^{C}\right)$ denote the high-type expected profit in signing the contract $\left[P^{C}, L^{C}\right]$. We have:

$$
E \pi_{h}\left(P^{C}, L^{C}\right)=\left(I_{1}+I_{2}\right)\left(p_{h}(1+\mu)-1\right)-\rho \hat{L}^{C} .
$$

The expected profit is equal to the first-best profit less the signalling cost $\rho R^{C}$ that derives from the fact that the high-type bank signals its type by paying a penalty if one of the loans defaults (and in this way it covers part of the losses of the risk buyer in case of default). Note that the capital loss is decreasing in the cost of capital $\rho$ since it enters negatively in the low-type bank constraint and therefore it reduces the 
incentive of the low-type bank to sign this type of contract. The separating equilibrium that satisfies the CK-criterion is the strategy profile in which high-type banks offer the contract $\left[P^{C}, L^{C}\right]$ and low-type banks offer full-coverage plain vanilla contracts at the fair price $\left(1-p_{l}\right)\left(I_{1}+I_{2}\right)$. Risk-buyer beliefs are such that a bank is high-type with probability 1 if it offers the contract $\left[P^{C}, L^{C}\right]$; it is a low-type with probability one otherwise. The same argument presented in the proof of proposition 1 proves that this contract is the unique one satisfying the CK-criterion.

\section{Proof of Lemma 1}

In any separating equilibrium the expected profit of the low-type bank is:

$$
E \pi_{l}=\left(I_{1}+I_{2}\right)\left(p_{l}(1+\mu)-1\right)
$$

If the low-type bank deviates, signs the contract $\left[P^{C}, L^{C}\right]$, and hedges the repayment $L^{C}$ by means of a hedging contract bought at price $\left(1-p_{l}^{2}\right) L^{C}$, it obtains:

$$
E \pi_{l}\left(P^{C}, L^{C}\right)=\left(I_{1}+I_{2}\right)\left(p_{h}(1+\mu)-1\right)-\left(p_{h}^{2}-p_{l}^{2}\right) L^{C}
$$

An easy calculation shows that $E \pi_{l}\left(P^{C}, L^{C}\right)>E \pi_{l}$ if and only if:

$$
\mu<\frac{p_{h}+p_{l}-p_{l} p_{h}}{p_{l} p_{h}}
$$

that is true by the assumption that $\mu<1$.

Proof of Proposition 3: If the credit derivative market is opaque the risk seller can secretly hedge its risk exposure with the Binary CDB contract, without the risk-buyer being informed.

In this case, the optimal separating contract $\left[P^{N C}, L^{N C}\right]$ solves the following problem:

$$
\max _{\{P, L\}} P-\left(1-p_{h}^{2}\right) L+\rho\left(\min \left\{0, P-L-\left(I_{1}+I_{2}\right)\right\}\right)-\left(I_{1}+I_{2}\right)
$$


s.t.

$$
\begin{gathered}
P-\left(1-p_{l}^{2}\right) L \leq p_{l}\left(I_{1}+I_{2}\right)(1+\mu) \\
p_{h}\left(I_{1}+I_{2}\right)(1+\mu)+\left(1-p_{h}^{2}\right) L-P \geq 0 .
\end{gathered}
$$

Note that the cost of capital does not enter in the low-type bank's self selection constraints since a low-type can always fully hedge the payment of the fixed amount $L$ at its fair price $\left(1-p_{l}^{2}\right) L$. Hence a natural candidate to be the optimal separating contract is the contract $\left[P^{N C}, L^{N C}\right]$, the optimal separating contract when capital is costless. Consider the strategy profile such that high-type banks sign contracts $\left[P^{N C}, L^{N C}\right]$ and low-type banks sign CDS basket contracts. The only system of beliefs consistent with this strategy profile is such that the risk-buyer assigns probability one that the bank is high-type if it offers the contract $\left[P^{N C}, L^{N C}\right]$, and probability one that the bank is low-type if it offers a different contract, namely a plain vanilla contract. The high-type bank expected profits, if it signs the contract $\left[P^{N C}, L^{N C}\right]$, are equal to:

$$
E \pi_{h}\left(P^{N C}, L^{N C}\right)=\left(I_{1}+I_{2}\right)\left(p_{h}(1+\mu)-1\right)-\rho R^{N C}
$$

where $\rho R^{N C}=\rho\left(\left(I_{1}+I_{2}\right) \frac{\left(\left(p_{h}+p_{l}\right)-(1+\mu) p_{h} p_{l}\right)}{\left(p_{h}+p_{l}\right)}\right)$ is the cost of capital as before. The separating equilibrium exists only if high-type banks do not deviate and buy CDS basket contracts as low-types. The optimal deviation for the high-type bank is buying a hedging contract of amount $X$ at a unit price of $\left(1-p_{l}^{2}\right)$, such that:

$$
X-\left(1-p_{l}^{2}\right) X-R^{N C}=0,
$$

that is,

$$
X=\frac{R^{N C}}{p_{l}^{2}} .
$$


Let $E \pi_{h}\left(P^{N C}, L^{N C}, X\right)$ denote the expected profits of the high-type bank when it signs a contract $\left[P^{N C}, L^{N C}\right]$, and a plain vanilla contract of amount $X$ as a low-type. Then, we have that:

$$
E \pi_{h}\left(P^{N C}, L^{N C}, X\right)=\left(I_{1}+I_{2}\right)\left(p_{h}(1+\mu)-1\right)-\left(p_{h}^{2}-p_{l}^{2}\right) X
$$

and $E \pi_{h}\left(P^{N C}, L^{N C}\right) \geq E \pi_{h}\left(P^{N C}, L^{N C}, X\right)$ if and only if

$$
\rho \leq \frac{p_{h}^{2}-p_{l}^{2}}{p_{l}^{2}} .
$$

If $\rho>\frac{p_{h}^{2}-p_{l}^{2}}{p_{l}^{2}}$ then the contract $\left[P^{N C}, L^{N C}\right]$ does not sustain a separating equilibrium in which a low-type bank only buys the CDS basket contract at its fair price. The separating equilibrium exists only if there is no capital requirement for the bank loan portfolio, and therefore the optimal separating contract $\left[P^{O}, L^{O}\right]$ satisfies the following problem:

$$
\max _{\{P, L\}} P-\left(1-p_{h}^{2}\right) L-\left(I_{1}+I_{2}\right)
$$

s.t.

$$
\begin{gathered}
P-\left(1-p_{l}^{2}\right) L-p_{l}\left(I_{1}+I_{2}\right)(1+\mu) \leq 0 \\
p_{h}\left(I_{1}+I_{2}\right)(1+\mu)+\left(1-p_{h}^{2}\right) L-P \geq 0 .
\end{gathered}
$$

The solution of this maximization problem is the following:

$$
\begin{gathered}
P^{O}=\frac{\left(I_{1}+I_{2}\right)\left(p_{l}(1+\mu)-1+p_{l}^{2}\right)}{p_{l}^{2}} \\
L^{O}=\frac{\left(I_{1}+I_{2}\right)\left(p_{l}(1+\mu)-1\right)}{p_{l}^{2}} .
\end{gathered}
$$

A further constraint is added with respect to the case with no capital requirements. The effect of capital requirements and opacity turn out to be similar to a liquidity constraint such that in no state of the world does the bank face negative cash-flows. The high-type bank profits are equal to $E \pi_{h}\left(P^{O}, L^{O}\right)=\frac{p_{h}^{2}}{p_{l}^{2}}\left(I_{1}+I_{2}\right)\left(p_{l}(1+\mu)-1\right)$. 
Proof of Lemma 2: By simply comparing the two levels of profits we have that the level of profits of the pooling equilibrium is higher if:

$$
\left(I_{1}+I_{2}\right)-\left(q\left(1-p_{h}\right)+(1-q)\left(1-p_{l}\right)\right)\left(I_{1}+I_{2}\right)(1+\mu) \geq p_{h}^{2} \frac{\left(I_{1}+I_{2}\right)\left(p_{l}(1+\mu)-1\right)}{p_{l}^{2}}
$$

that is,

$$
q \geq \frac{p_{h}^{2}\left(\frac{(1+\mu)}{p_{l}}-p_{l}^{2}\right)-\mu-\left(1-p_{l}\right)(1+\mu)}{\left(p_{h}-p_{l}\right)(1+\mu)}
$$

Proof of Proposition 4: First, suppose that there exists an optimal separating contract $(\tilde{P}, \tilde{g}(s))$ such that the function $\tilde{g}(s)$ is positive in a neighborhood of $s^{\prime}>s_{0}$, i.e. $\tilde{g}(s)>0$ for all $s \in\left[s^{\prime}-\varepsilon, s^{\prime}+\varepsilon\right]$. Let $\tilde{s} \in \arg \max \tilde{g}(s)$. Consider a function $g(s)$ such that $\int_{0}^{s_{o}} g(s) f_{l}(s) d s=\int_{0}^{s_{o}} \tilde{g}(s) f_{l}(s) d s$ and $g(s)=0$ for $s>s_{0}$ and a price:

$$
P=\min \left\{\int_{0}^{s_{0}} g(s) f_{h}(s) d s+E_{h}(s)+\rho R^{S}, E_{l}(s)+\int_{0}^{s_{0}} g(s) f_{l}(s) d s+\rho R^{S}\right\}
$$

where $R^{S}=\min \{0, P-I-g(\bar{s})\}$.

If the contract $[\tilde{P}, \tilde{g}(s)]$ is separating, then the contract $[P, g(s)]$ is separating too. Moreover $\tilde{g}(\tilde{s}) \geq g(\bar{s})$ and the contract $[P, g(s)]$ provides to the high-type banks a larger or equal level of profits.

Second, suppose that there exists an optimal contract $[\tilde{P}, \tilde{g}(s)]$ where $\tilde{g}(s)=0$ for all $s \geq s_{0}$ and there exist a pair $s^{\prime}, s^{\prime \prime}<s_{0}$ with $\tilde{g}\left(s^{\prime}\right)>\tilde{g}\left(s^{\prime \prime}\right)$. Let $\tilde{s} \in \arg \max \tilde{g}(s)$. Let $E_{i}(s)$ denote the conditional expected value of the asset owned by type $i=h, l$. Since the contract $[\tilde{P}, \tilde{g}(s)]$ is separating, then high-type profits are at most $E_{h}(s)-$ $I+\rho(\min \{0, P-I-g(\bar{s})\})$. Consider now a continuous function $g(s)=k$ (where $k$ is a constant and does not depend on $s$ ) for all $s \leq s_{0}$ (and $g(s)=0$ otherwise) and a contract $[P, k]$ such that:

$$
\begin{aligned}
& P=k F_{h}\left(s_{0}\right)+E_{h}(s) \\
& P=k F_{l}\left(s_{0}\right)+E_{l}(s) .
\end{aligned}
$$


By construction, the contract $[P, k]$ is separating and it follows that $\tilde{g}(\tilde{s})>k$ : therefore high-type banks' profits are larger or equal, by signing a contract $[P, k]$, than by signing a contract $[\tilde{P}, \tilde{g}(s)]$. Solving the above equations we obtain:

$$
k=\frac{E_{h}(s)-E_{l}(s)}{F_{l}\left(s_{0}\right)-F_{h}\left(s_{0}\right)}
$$

and:

$$
P=\frac{E_{h}(s) F_{l}\left(s_{0}\right)-E_{l}(s) F_{h}\left(s_{0}\right)}{F_{l}\left(s_{0}\right)-F_{h}\left(s_{0}\right)}
$$

